Article

\title{
Big Five Personality Traits and Life Satisfaction: The Mediating Role of Religiosity
}

\author{
Małgorzata Szcześniak*(D), Blanka Sopińska and Zdzisław Kroplewski \\ Institute of Psychology, Faculty of Humanities, University of Szczecin, Krakowska Street 69, \\ 71-017 Szczecin, Poland \\ * Correspondence: malgorzata.szczesniak@whus.pl
}

Received: 7 June 2019; Accepted: 3 July 2019; Published: 17 July 2019

check for updates

\begin{abstract}
Extensive empirical research conducted up till now has confirmed that personality represents one of the most significant predictors of life satisfaction. Still, no studies to date have empirically tested the path of influence from personality traits to religiosity and the effects of both on life satisfaction/positivity within the same model. In the current study, we aimed to verify whether the relationship between personality and satisfaction/positivity was mediated by religiousness, as it is considered motivational in nature. The sample consisted of 213 participants (72\% women) aged between 18 and 75 . The average age was approx. 32. We used the following tools: the NEO Five Factor Inventory, the Satisfaction with Life Scale, the Positivity Scale, the Personal Religiousness Scale, and the Intensity of Religious Attitude Scale. Our hypotheses (H1 and H2) found their confirmation to a large degree. In fact, life satisfaction positively correlated with extraversion, agreeableness, and conscientiousness. Moreover, life satisfaction negatively correlated with neuroticism. A similar pattern of results, even slightly stronger, was found in the case of positivity and personality traits. Contrary to our assumptions, neither life satisfaction nor positivity correlated with openness to experience. Extraversion and agreeableness correlated positively with religious attitude, personal religiousness and its four dimensions. Conscientiousness correlated positively only with faith, personal religiousness, and religious attitude. We also found negative and significant correlations between openness and all of the dimensions of personal religiousness. A lack of correlation was found between: (1) neuroticism and all of the dimensions of religiosity; (2) conscientiousness and religious practices, and religious self. Our research offers a contribution to the field by providing evidence that some personality traits predict life satisfaction/positivity because respondents display a personal religiousness/religious attitude.
\end{abstract}

Keywords: personality traits; life satisfaction; positivity; personal religiousness; intensity of religious attitude

\section{Introduction}

The relationship between personality and life satisfaction has received substantial attention in recent years (Hounkpatin et al. 2018). A review of related quality-of-life studies shows two approaches that provide a theoretical explanation of factors which contribute to people's subjective well-being (SWB): bottom-up and top-down theories (Brief et al. 1993). The bottom-up perspective postulates that global satisfaction is influenced by situational and environmental factors, such as: education, marriage, childbirth, standard of living, starting a new job, income, job loss, adoption, divorce, remarriage, relocating, health, disease, and death (Brief et al. 1993; Diener et al. 2003; Heidemeier and Göritz 2016; Luhmann et al. 2013). People evaluate their lives through a summation of enjoyable and unpleasant moments. Happy individuals are happy because they experience many lucky events (Brief et al. 1993). In contrast, the top-down model argues that happiness depends on stable personality characteristics or dispositional factors (e.g., self-esteem, attitudes, beliefs, neuroticism, extraversion, optimism, 
pessimism) (Brief et al. 1993; Diener et al. 2003). Happy individuals are happy because they enjoy life despite the circumstances (Brief et al. 1993). Although both personality and life satisfaction have been jointly examined, no studies to date have empirically tested the path of influence from personality traits to religiosity and the effects of both on life satisfaction/positivity within the same model.

\subsection{Personality and Life Satisfaction}

Extensive empirical research conducted up till now has confirmed that personality represents one of the most significant predictors of life satisfaction (DeNeve and Cooper 1998; Schimmack et al. 2004; Heidemeier and Göritz 2016) and plays a much greater role in controlling an individual's level of subjective well-being than was previously believed (Steel et al. 2008). Most of the studies based on the model of the Big Five confirm that people with different traits show different levels of satisfaction within several domains of human functioning (Joshanloo and Afshari 2011; Schimmack et al. 2004). For example, Heidemeier and Göritz (2016) reported bivariate correlations between life satisfaction and neuroticism $\left(-0.33^{* *}\right)$, extraversion $\left(0.18^{* *}\right)$, agreeableness $\left(0.10^{* *}\right)$, openness to experience $\left(0.05^{* *}\right)$, and consciousness $\left(0.20^{* *}\right)$. Such results are understandable in the context of the Big Five personality theory. In fact, neuroticism alludes to individual differences in negative responses to threats (Lahey 2009), extraversion refers to positive emotions (Lucas et al. 2008), openness involves attentiveness to inner feelings (Koenig et al. 2012), agreeableness shapes social attitudes through trust and modesty (Costa et al. 1991), and conscientiousness expresses the need for achievement and commitment (Costa et al. 1991). Xu et al. (2017) found a similar pattern of results. However, based on a meta-analysis of 2142 correlation coefficients derived from 347 samples, Steel et al. (2008) concluded that only neuroticism, extraversion, agreeableness, and consciousness were significantly related to all subjective well-being facets measured. Some other researchers (Heidemeier and Göritz 2016; Joshanloo and Afshari 2011; Stolarski and Matthews 2016; Xu et al. 2017) indicated that openness to new experiences appears to be a rather weak and inconsistent correlate and/or predictor of life satisfaction. Moreover, the literature relevant to the assessment of the relationship between personality and satisfaction through regression analysis shows that personality has a strong influence on life satisfaction (Schimmack et al. 2004), hedonic balance and subjective well-being (Costa and McCrae 1980). The results confirm that the depression facet of neuroticism and the positive emotions/cheerfulness facet of extraversion are the strongest and most consistent predictors of life satisfaction (Schimmack et al. 2004).

Previous studies have also shown that the Big Five factors correlate with positive orientation which comprises three self-belief dimensions: self-esteem, optimism, and satisfaction with life. The outcomes of research on a large sample of American, Italian, Japanese, Spanish (Caprara et al. 2012b), and Polish respondents (Błachnio and Przepiórka 2016) revealed that all dimensions of the Big Five model (the positive pole of extraversion-energy, emotional stability—the reverse of neuroticism, agreeableness, conscientiousness, and openness) correlated with a positive orientation. An analogous configuration of results was found by Miciuk et al. (2016) with the difference that a hypothesis about a positive correlation between positive orientation and openness, and agreeableness was not supported.

\subsection{Personality and Religiosity}

Determining how personality is related to religious beliefs and practices has been an important topic for the psychological research of religion (Aghababaei et al. 2014; Henningsgaard and Arnau 2008; Hills et al. 2004). Before the 1980s, much of the published studies directed their interest towards the relationship between religiosity and Eysenck's three-factor model of personality (Eysenck 1998; Henningsgaard and Arnau 2008; Jorm and Christensen 2004). A series of outcomes confirmed that religious people tended to be slightly lower in psychoticism than those who considered themselves less religious (Duriez et al. 2004; Francis 1992). Nevertheless, in recent years more researchers have started to use the Big Five model to define an association between this trait structure and religiosity. A meta-analytic review of recent studies (Saroglou 2002) showed that open-mature religiosity and spirituality correlate positively with agreeableness, conscientiousness, extraversion, and openness, and negatively with neuroticism. These results are consistent across age, gender, country, cohort, 
religious tradition, and measures assessing personality and religiosity (Saroglou 2010). Likewise, Ferrari et al. (2017) found that honesty-humility and extraversion were significant predictors of religious commitment, and extraversion and openness to experience were significant predictors of spiritual beliefs.

\subsection{Personality, Life Satisfaction, and Religiosity}

According to Heidemeier and Göritz (2016), the Big Five personality traits may show different relationships with life satisfaction depending on individual differences. Another explanation of different associations between both variables is the presence of mediating or moderating mechanisms that link personality and subjective well-being (Xu et al. 2017). Among factors investigated, more often there have been: age and gender (Steel et al. 2008), self-esteem (Joshanloo and Afshari 2011; Weidmann et al. 2017), emotion regulation (Vater and Schröder-Abé 2015), gratitude (Szcześniak et al. 2019) or coping styles (Xu et al. 2017). However, as Chukwuorji et al. (2018) pointed out, religiosity, which is viewed as motivational in nature, cannot be omitted from mediators of well-being. Religious beliefs affect subjective well-being, with religious people mostly being happier than non-religious people, regardless of their faith (Berthold and Ruch 2014; Dolan et al. 2008; Habib et al. 2018). Moreover, results in a sample of UK adults demonstrated that intrinsic orientation and positive religious coping were significantly associated with higher psychological well-being that reflects human growth, positive functioning and existential life challenges (Lewis et al. 2005). Other researchers (Maltby et al. 1999) found that frequency of personal prayer was the leading component in the relationship between religiosity and well-being. Krok (2014) observed that a religious belief system allows individuals to discover or regain meaning in challenging life events and times of stress. Unterrainer et al. (2010) provided evidence that religiosity and spirituality have a salutogenic function, and are correlated with psychological well-being and some personality traits (extraversion, neuroticism, and openness).

\subsection{Research Problem and Hypotheses}

Drawing from the evidence provided by researchers that personality is not the only predictor of life satisfaction, and that relations between variables are often more complex than simple bivariate relations (Fairchild and MacKinnon 2009), we assumed that personal religiosity might modify the direct association between personality traits and satisfaction. Likewise, Sullivan (2001) emphasised that religiosity could either have direct, indirect, or compensative effects. Therefore, the purpose of this study was twofold. First, we assessed psychological correlates and determinants of life satisfaction/positive orientation. Second, we focused on the mediating role of personal religiousness/religious attitude between personality traits and satisfaction with life/positive orientation.

Altogether the existing religion-personality literature and the above-mentioned outcomes seem to justify the following hypotheses:

Hypothesis 1 (H1). Domains of personality correlate with life satisfaction/positivity in such a way that neuroticism is negatively related to life satisfaction/positivity, and the remaining domains (extraversion, openness, agreeableness, and conscientiousness) are positively related to life satisfaction/positivity.

Hypothesis 2 (H2). Domains of personality correlate with personal religiousness/religious attitude in such a way that neuroticism is not related to personal religiousness/religious attitude, openness is negatively related to personal religiousness/religious attitude, and the remaining domains (extraversion, agreeableness, and conscientiousness) are positively related to personal religiousness/religious attitude.

Hypothesis 3 (H3). Personal religiousness/religious attitude mediates the effect of personality domains on life satisfaction/positivity. 
Hypothesis $\mathrm{H} 3$ can cause some doubts, as the suitability of a cross-sectional design for studying mediation is still being discussed (Aguinis et al. 2017; Maxwell and Cole 2007). Nevertheless, MacKinnon and colleagues (MacKinnon et al. 2012) recall that indirect effect is implicit in social science theories and affirm that cross-sectional data necessitate additional theoretical assumptions or empirical evidence if they are to be inferred in a causal manner. Hence, taking into account the requirement of a theory and/or empirical-derived mediation hypothesis (Agler and Boeck 2017), we applied the simplest mediation model (MacKinnon et al. 2012): an antecedent variable (Big Five personality traits) affects a hypothesised intermediating variable (religiosity), which in turn affects a dependent variable (life satisfaction).

In this respect, the literature relevant to the assessment of the relationship between personality and religiousness (McCrae 1999) shows that people with certain personality traits may be more or less likely to display positive or negative religious beliefs, attitudes, and practices (Saroglou 2015; Saroglou and Muñoz-García 2008). For example, neuroticism and self-actualisation are recognised as negative predictors, and horizontal self-transcendence is established as a positive predictor of self-rated religiosity (Schnell 2012). It is all because personality can be thought of as a much more solid framework for grasping religion than vice versa (Maltby et al. 2007). In other words, it is more likely that personality influences religion than religion influences personality as the first is biologically based and the latter is learned. This view is supported by some longitudinal findings (Wink et al. 2007) suggesting that personality traits in a transitional stage of adolescence predict religiousness in late adulthood whereas empirical evidence for the reverse effect is infrequent. Moreover, religion is an important factor that affects well-being in different social contexts (Kortt et al. 2015; Sinnewe et al. 2015; ten Kate et al. 2017; Yeniaras and Akarsu 2017). Even after controlling for personality factors, interest in religion, intrinsic and extrinsic-personal religiosity are still reasonably strong predictors of happiness and life satisfaction (Aghababaei 2014). Some authors (Emmons 2005; Krok 2014; ten Kate et al. 2017; Zarzycka et al. 2017) pointed out that being religious provides a sense of meaning and security, offering an important benefit to satisfaction with life. On the bases of these theoretical and empirical promises, we assumed that religiosity might be an intermediating variable in the relationship between personality traits and life satisfaction.

\section{Materials and Methods}

\subsection{Ethics Approval}

The study and the protocol were approved by the Bioethics Committee of the Institute of Psychology at the University of Szczecin and conducted according to the Declaration of Helsinki.

\subsection{Participants}

The sample consisted of 213 participants (72\% women) aged between 18 and 75 . The average age was approx. $32(M=31.81 ; S D=13.13)$. The biggest group was formed by working respondents $(46 \%)$, followed by students (39\%), unemployed (9\%), and pensioners (6\%). In terms of place of residence, $26 \%$ of participants declared living in the country, $8 \%$-in a town with fewer than 5000 inhabitants, $23 \%$ - between 5000 and 50,000, 15\% - between 50,000 and 200,000, and 28\% -in a city with over 200,000 inhabitants.

\subsection{Data Collection}

The participants were recruited through designated online Internet communities and different groups. All of the respondents who decided to take part in the study were given general information about the study aims and were prompted with a web-based informed consent. Only after giving their agreement, the participants were asked to fill in the questionnaires. Respondents under the age of 18 were excluded from participation. 


\subsection{Assessment of the NEO Five-Factor Inventory (NEO FFI)}

NEO FFI, designed by Costa and McCrae (1989) and adapted by Zawadzki and colleagues (Zawadzki et al. 1998), is a questionnaire of 60 items that assesses the five domains of personality: neuroticism, extraversion, openness, agreeableness, and conscientiousness. Neuroticism refers to the tendency to experience psychological distress and negative emotions in the context of a stressful situation. Extraversion denotes the degree of sociability and positive emotions. Openness indicates openness to experience. Agreeableness signifies the tendency of being friendly, compassionate, altruistic, and cooperative. Conscientiousness refers to one's level of self-control in planning and following through on goals. Participants rate each item on a 5-point Likert-type scale (from $1=$ strongly disagree to $5=$ strongly disagree) (Rosellini and Brown 2011). In the current study, each of the five domains of the NEO FFI had adequate internal consistency. The Cronbach $\alpha$ of neuroticism was 0.88 , of extraversion was 0.78 , of openness was 0.70 , of agreeableness was 0.75 , and of conscientiousness was 0.85 .

\subsection{Assessment of the Satisfaction with Life Scale (SWLS)}

SWLS, originated by Diener et al. (1985) and (Diener 1998) and adapted by Juczyński (2001), is a short 5-item scale that measures the relatively global and stable judgmental component of subjective well-being. The respondents evaluate each of five statements by using multiple-choice answers on a 7-point Likert scale that ranges from $1=$ strongly disagree to $7=$ strongly agree. Items are added up to yield a total score of satisfaction. The possible range of scores is between 5 and 35 . The higher the final score, the more intense is the general life satisfaction. The original study (Diener et al. 1985) reports a good coefficient alpha of 0.82 . In the present survey, the Cronbach's alpha was 0.83 and good internal consistency was demonstrated.

\subsection{Assessment of the Positivity Scale (PS)}

PS, designed by Caprara (2009) and Caprara et al. (2012a, 2012b) and adapted by Łaguna et al. (2011), is a short 8-item instrument that measures a basic disposition to view one's self, one's life and future experience with a positive outlook. Participants answer on a 5-point scale from $1=$ strongly disagree to $5=$ strongly agree. A total score is calculated by summing all eight items (one reversed) that load on a single latent factor (Caprara et al. 2012a, 2012b). Higher scores reflect a higher general predisposition to view life in a positive manner (Tian et al. 2018). Previous research has revealed that the PS demonstrated good reliability exceeding 0.80 (Łaguna et al. 2011). In the current study, the Cronbach's alpha coefficient was 0.84 .

\subsection{Assessment of the Personal Religiousness Scale (PRS)}

PRS, developed by Jaworski $(1989,2002)$, is a self-report scale assessing personal religiousness. The questionnaire contains 30 statements and measures four aspects of religiosity: (1) faith-belief in God, perceived as a loving and merciful Father; a sense of a personal and inner tie with God; (2) morality—a sense of responsibility for own thoughts and deeds; coherence between religious beliefs and daily moral behaviour; willingness to read and follow God's will; (3) religious practices-a level of religious involvement in the relationship with God through prayer of thanksgiving and intercession, contemplation and meditation; commitment to the life of the Church; (4) religious self-a strong sense of God's closeness among daily activities; pride in being a Christian. Respondents are invited to indicate on a 7-point Likert-type scale $(1=$ strongly disagree to $7=$ strongly agree $)$ the degree of their religiosity in four domains. The maximum score (210 points) indicates highly personal religiousness. The minimum score (30 points) suggests impersonal religiousness. The reliability coefficient of Cronbach's alpha in the present study was 0.95 . 


\subsection{Assessment of the Intensity of Religious Attitude Scale (IRAS)}

IRAS, designed by Prężyna (1968) and adapted by Śliwak and Bartczuk (2011), measures the intensity of the individual's approach towards the religious attitude object (God, the Church understood as a religious institution, and, speaking more precisely, the whole supernatural world). By the intensity of religious attitude Prężyna and Kwaśniewska (1974) mean the strength and determination with which the individuals stand by their attitudes. The scale consists of 20 statements, 10 of which must be reversed. Each item is evaluated on a 7-point Likert-type scale $(1=$ strongly disagree to $7=$ strongly agree). The scale's reliability of Cronbach $\alpha$ in this study was very high, amounting to 0.97 .

\subsection{Statistical Analysis}

For the analyses of statistical data, the Statistical Package for the Social Sciences (SPSS software version 20, IBM) was used with significance accepted if $p<0.05$. There was no problem with missing data as the statements of each online questionnaire needed to be $100 \%$ complete before continuing to the next section of questionnaires. The data distribution was checked by means of skewness and kurtosis to control how much the variables diverge from the normal curve (Morgan and Griego 1998). Descriptive statistics were computed, and Pearson's correlation coefficients for parametric data were calculated to investigate the association between variables including personality traits, life satisfaction/positivity, and personal religiousness/religious attitude.

The statistical power analysis program (Heinrich-Heine-Universität, Düsseldorf, Germany) used in the current study was G*Power 3.1.9.4 (Faul et al. 2007, 2009) to decide upon a suitable sample size (Anderson et al. 2017). We applied $t$ tests for linear multiple regression with a priori type of power analysis. We assumed the recommended higher power criteria of 0.95 (Anderson et al. 2017; Lakens 2013) and a critical significance level of $\alpha$ of 0.05 to detect a small and realistic effect size index of $\mathrm{f}^{2}=0.05$. The rationale for using the value of $\mathrm{f}^{2}$ was because there have only been a few studies on the relationship between personality traits and life satisfaction/positivity with religiosity as a potentially mediating variable. In the case of novel studies, Cohen (1988) recommends such an option. Furthermore, several researchers (Aguinis et al. 2017; Martell et al. 1996) maintain that as long as a small effect has a meaningful influence for science or practice, it should be taken into account in research projects. The $G^{*}$ Power analysis indicated that a power of 0.95 would necessitate a minimum sample size of 218 respondents.

Moreover, we used a linear regression model to control for the presence of possible confounders and to examine if they were not affecting the actual relationship between the dependent and the independent variables (Pourhoseingholi et al. 2012). First, because we considered that personal religiousness, its four dimensions (faith, morality, religious practices, and religious self), and religious attitude could share substantial amounts of information while accounting for covariates, we examined whether there would be a high redundancy among predictors, and the multicollinearity problem. To detect collinearity, we used an index of tolerance statistics and variance inflation factors (VIF) (Hahs-Vaughn 2017). Second, we checked the data for multivariate outliers, using Mahalanobis' distance and Cook's distance. Third, the respondents' sex and age were included to control for their potential effect on the relationship between the independent variable of personality traits and with the outcome variable (life satisfaction/positivity). As a matter of fact, both theoretical and empirical examinations of the impact of personality traits in relation to demographic variables found differences between women and men (South et al. 2018), and younger and older participants (Soto et al. 2011). The potential confounders were entered at Step 1. All variables hypothesised as predictors of life satisfaction/positivity were entered at Step 2.

The PROCESS macro (version 3.2) (Hayes 2017) was run to observe whether personal religiosity and religious attitude mediated the association between the five dimensions of personality separately, and life satisfaction/positivity.

Neuroticism, extraversion, openness to experience, agreeableness, and conscientiousness were the independent variables, and life satisfaction/positivity were the dependent variables. Personal religiosity 
and religious attitude acted as mediating variables (separately). Hence, there were ten single-level mediation models (according to Hayes 2017, we applied Model no. 4), consisting of three-variable systems. For the present investigation, bootstrapping procedures were completed. As suggested by Preacher and Hayes (2008), 5000 bootstrap samples and 95\% confidence intervals were employed to assess the indirect effects that are considered significant if they do not include zero. This method is acknowledged to be more powerful than traditional mediation analyses, as it does not require the normality of the sampling distribution (Hayes 2017).

\section{Results}

\subsection{Preliminary Analyses}

Five domains of personality, life satisfaction, positivity, and dimensions of religiousness were assessed for skewness and kurtosis to estimate the normality of the scale's distribution. We adopted values less than the \pm 2 generally considered suitable for a normal distribution (George and Mallery 2016). No variables surpassed the cut-offs of \pm 2 (Table 1 ).

Table 1. Descriptive statistics for the NEO Five-Factor Inventory, Satisfaction with Life Scale, Positivity Scale, Personal Religiousness Scale, and Intensity of Religious Attitude Scale $(N=213)$.

\begin{tabular}{lcccc}
\hline \multicolumn{1}{c}{ Scales } & $\boldsymbol{M}$ & $\boldsymbol{S D}$ & Skewness & Kurtosis \\
\hline 1. NE & 35.92 & 9.66 & -0.018 & -0.332 \\
2. EX & 39.29 & 6.91 & -0.318 & 0.040 \\
3. OP & 39.04 & 6.44 & 0.271 & -0.139 \\
4. AG & 41.60 & 6.21 & -0.255 & -0.188 \\
5. CO & 43.49 & 7.41 & -0.203 & -0.293 \\
6. LS & 21.21 & 5.64 & -0.212 & -0.308 \\
7. PO & 28.21 & 5.05 & -0.738 & 1.022 \\
8. FA & 26.21 & 7.11 & -0.028 & -0.568 \\
9. MO & 21.50 & 7.38 & -0.257 & -0.927 \\
10. RP & 28.62 & 9.33 & 0.151 & -0.991 \\
11. RS & 20.08 & 5.89 & -0.363 & -0.530 \\
12. PR & 96.42 & 27.97 & -0.083 & -0.949 \\
13. RA & 98.13 & 31.44 & -0.606 & -0.406 \\
\hline
\end{tabular}

Neuroticism (NE); Extraversion (EX); Openness (OP); Agreeableness (AG); Conscientiousness (CO); Life satisfaction (LS), Positivity (PO); Faith (FA); Morality (MO); Religious practices (RP); Religious self (RS); Personal religiousness (PR); Religious attitude (RA).

\subsection{Correlation Analysis}

Our hypotheses (H1 and H2) found their confirmation to a large degree (Table 2). In fact, life satisfaction positively correlated with extraversion, agreeableness, and conscientiousness. Moreover, life satisfaction negatively correlated with neuroticism. A similar pattern of results, even slightly stronger, was obtained in the case of positivity and personality traits. Contrary to our assumptions, neither life satisfaction nor positivity correlated with openness to experience. In other words, it was confirmed that the more sociable, compassioned, responsible, and less negative-affected respondents tended to declare higher life satisfaction and positivity than individuals who acknowledged that they were less outgoing, empathetic, reliable, and more negative. At the same time, extraversion and agreeableness correlated positively with religious attitude, personal religiousness and its four dimensions. Conscientiousness correlated positively only with faith, personal religiousness, and religious attitude. According to our hypothesis, we found negative and significant correlations between openness and all of the dimensions of religiosity, and a lack of correlations between neuroticism and all of the dimensions of religiosity. In the large majority of cases, these relationships were found to be statistically significant at $p$-values $<0.01$. 
Table 2. Correlation matrix between personality traits, life satisfaction/positivity, and dimensions of religiousness/religious attitudes $(N=213)$.

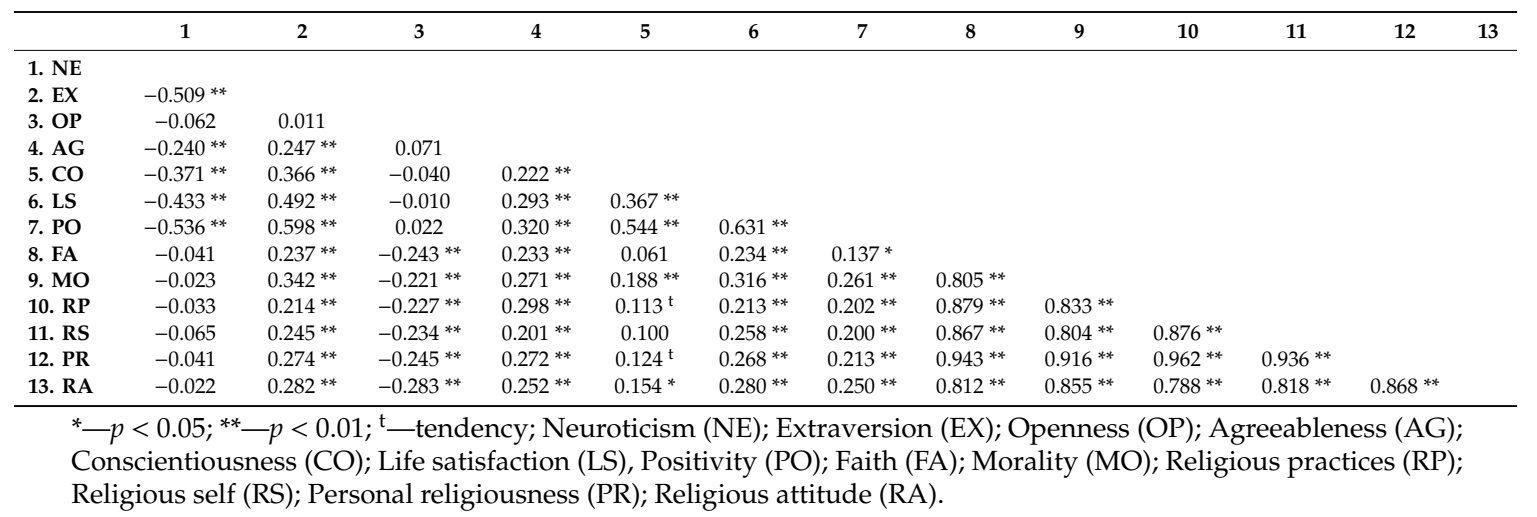

Therefore, on the basis of our results, it seems that people who are outgoing, sympathetic, compassionate, and less open to experience tend to have a sense of God's love and closeness, personal responsibility for their thoughts and deeds, religious involvement and determination with which they stand by their attitudes.

\subsection{Multicollinearity and Confounding Variables}

Although there is no consensus regarding which VIF cutoff score is most appropriate for collinearity (Thompson et al. 2017), we considered a VIF index exceeding 5.0 (Hahs-Vaughn 2017; Lomax and Hahs-Vaughn 2012) and a tolerance value of less than 0.2 as indicative of a potential multicollinearity problem (Mehmetoglu and Jakobsen 2017). Given that the analysis of multiple regression yielded a VIF of $1.04-4.30$ and a tolerance rate ranging from 0.23 to 0.85 , multicollinearity indexes indicated little evidence of multicollinearity for these data. Mahalanobis' distance procedure was conducted, using the chi-square distribution with a very conservative probability estimate for a case being an outlier $(p<0.001)$ (Fidell and Tabachnick 2003). None of the 213 cases were detected as a probable multivariate outlier. Moreover, Cook's value (between 0.000 and 0.061 ) was well under the point at which the investigator should be worried (less than 1) (Fidell and Tabachnick 2003), implying that the cases were not likely problematic in terms of having an excessive effect on the model (Lomax and Hahs-Vaughn 2012). Hierarchical regression analyses showed that neither sex nor age made a significant unique contribution to the model, explaining only $0.1 \%$ of variance $\left(R^{2}=0.001\right)$ : $\operatorname{sex}(\beta=-0.058, \mathrm{t}=-0.947, p=0.345)$ and age $(\beta=-0.112$, $\mathrm{t}=-1.844, p=0.067)$. Predictors explained an additional $38 \%$ of the variance, even after controlling for the effects of potential confounders.

\subsection{Mediational Analyses}

For the purpose of further inquiry into the association between the personality traits and life satisfaction/positivity, personal religiousness and religious attitude were introduced as potential mediators which could decrease, reinforce or have no impact on the existing correlation between the independent variables (personality traits) and the dependent variable (life satisfaction/positivity) (Figure 1). We did not include dimensions of personal religiousness as mediators because they were strongly correlated with general personal religiosity. Table 3 shows the statistics related to each mediation path for life satisfaction and Table 4 displays the statistics for positivity.

The results achieved through bootstrap sampling (5000) with a 95\% confidence interval revealed a significant role of personal religiousness as a mediator in the following relationships (Tables 3 and 4): extraversion-life satisfaction; openness to experience-life satisfaction/positivity; and agreeablenesslife satisfaction.

Religious attitude was a mediator between: extraversion—life satisfaction; openness to experiencelife satisfaction/positivity; agreeableness—life satisfaction/positivity; and conscientiousness-life 
satisfaction/positivity. In all of these cases, the original path $\mathrm{c}$ dropped to $c^{\prime}$ as a result of including the mediator. According to the obtained results, it can be affirmed that religiosity did not have a mediatory effect only in the relationship between neuroticism and life satisfaction/positivity.

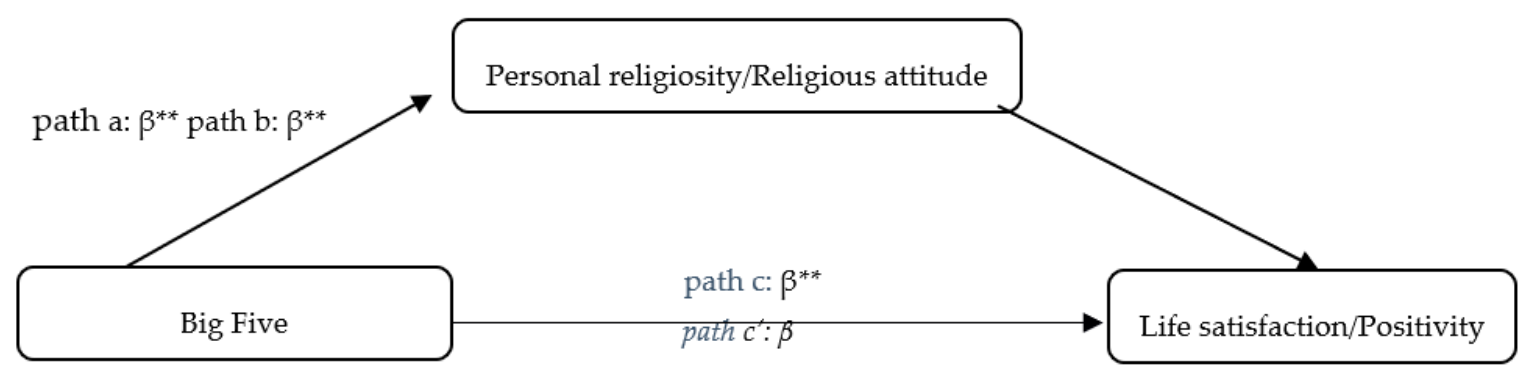

Figure 1. Theoretical model of the role of the mediator in the relationship between five dimensions of personality and life satisfaction/positivity. ${ }^{* *} p<0.01$. 
Table 3. The role of personal religiousness/religious attitude in the relationship between the Big Five dimensions of personality and life satisfaction ( $\mathrm{N}=213$ ).

\begin{tabular}{|c|c|c|c|c|c|c|}
\hline & a path & b path & c path & $\mathrm{c}^{\prime}$ path & Indirect Effect and B (SE) & 95\% CI LOWER UPPER \\
\hline 1. NE-PR-LS & $-0.11(\mathrm{ni})$ & $-0.05^{* * *}$ & $-0.25^{* * *}$ & $-0.25^{* * *}$ & $-0.0060(0.0108)$ & $-0.0289 ; 0.0137$ \\
\hline 2. $N E-R A-L S$ & -0.07 (ni) & $0.04^{* * *}$ & $-0.25^{* * *}$ & $-0.25^{* * *}$ & $-0.0034(0.0126)$ & $-0.0303 ; 0.0208$ \\
\hline 3. $\mathrm{EX}-\mathrm{PR}-\mathrm{LS}$ & $1.10^{* * *}$ & $0.03^{*}$ & $0.40^{* * *}$ & $0.36^{* * *}$ & $0.0323(0.0168)$ & $0.0036 ; 0.0690$ \\
\hline 4. $\mathrm{EX}-\mathrm{RA}-\mathrm{LS}$ & $1.28^{* * *}$ & $0.03 *$ & $0.40^{* * *}$ & $0.36^{* * *}$ & $0.0353(0.0181)$ & $0.0050 ; 0.0753$ \\
\hline 5. OP-PR-LS & $-1.06^{* * *}$ & $0.05^{* * *}$ & -0.01 (ni) & 0.05 (ni) & $-0.0608(0.0223)$ & $-0.1080 ;-0.0222$ \\
\hline 6. $\mathrm{OP}-\mathrm{RA}-\mathrm{LS}$ & $-1.37^{* * *}$ & $0.06^{* * *}$ & -0.01 (ni) & 0.06 (ni) & $-0.0746(0.0254)$ & $-0.1286 ;-0.0302$ \\
\hline 7. $A G-P R-L S$ & $1.22 * * *$ & $0.04^{* *}$ & $0.26^{* * *}$ & $0.21 * * *$ & $0.0503(0.0215)$ & $0.0024 ; 0.0166$ \\
\hline 8. $A G-R A-L S$ & $1.27^{* * *}$ & $0.03 * *$ & $0.26^{* * *}$ & $0.21^{* * *}$ & $0.0504(0.0200)$ & $0.0142 ; 0.0918$ \\
\hline 9. $\mathrm{CO}-\mathrm{PR}-\mathrm{LS}$ & 0.46 (ni) & $0.04^{* * *}$ & $0.28^{* * *}$ & $0.25^{* * *}$ & $0.0214(0.0143)$ & $-0.0028 ; 0.0523$ \\
\hline 10. CO-RA-LS & $0.65^{* *}$ & $0.04^{* * *}$ & $0.27^{* * *}$ & $0.25^{* * *}$ & $0.0269(0.0156)$ & $0.0012 ; 0.0617$ \\
\hline
\end{tabular}

$* p<0.05 ;{ }^{* *} \overline{p<0.01 ; * * *} p<0.001$; ni-non-significant; 1. NE—PR—LS: Neuroticism—Personal religiousness—Life satisfaction; 2. NE—RA—LS: Neuroticism-Religious attitude-Life satisfaction; 3. EX-PR-LS: Extraversion-Personal religiousness—Life satisfaction; 4. EX-RA-LS: Extraversion—Religious attitude-Life satisfaction; 5. OP-PR-LS: Openness—Personal religiousness-Life satisfaction; 6. OP-RA—LS: Openness—Religious attitude-Life satisfaction; 7. AG—PR—LS: Agreeableness—Personal religiousness—Life satisfaction; 8. AG—RA—LS: Agreeableness—Religious attitude—Life satisfaction; 9. CO—PR—LS: Conscientiousness—Personal religiousness—Life satisfaction; 10. CO—RA—LS: Conscientiousness-Religious attitude-Life satisfaction; a path = effect of the predictor on the mediator; $b$ path = effect of the mediator on the outcome; $\mathrm{c}$ path $=$ effect of the predictor on the outcome; $\mathrm{c}^{\prime}$ path = direct effect of predictor on the outcome while controlling for the mediator.

Table 4. The role of personal religiousness/religious attitude in the relationship between the Big Five dimensions of personality and positivity $(\mathrm{N}=213$ ).

\begin{tabular}{|c|c|c|c|c|c|c|}
\hline & a Path & b Path & c Path & $c^{\prime}$ Path & Indirect Effect and B (SE) & 95\% CI LOWER UPPER \\
\hline 1. NE-PR-PO & $-0.11(\mathrm{ni})$ & $-0.03 * * *$ & $-0.28^{* * *}$ & $-0.27^{* * *}$ & $-0.0041(0.0076)$ & $-0.0212 ; 0.0097$ \\
\hline 2. $\mathrm{NE}-\mathrm{RA}-\mathrm{PO}$ & $-0.07(\mathrm{ni})$ & $0.04^{* * *}$ & $-0.28^{* * *}$ & $-0.27^{* * *}$ & $-0.0027(0.0097)$ & $-0.0232 ; 0.0160$ \\
\hline 3. $\mathrm{EX}-\mathrm{PR}-\mathrm{PO}$ & $1.10^{* * *}$ & 0.01 (ni) & $0.43^{* * *}$ & $0.42 * * *$ & $0.0108(0.0118)$ & $-0.0111 ; 0.0359$ \\
\hline 4. $\mathrm{EX}-\mathrm{RA}-\mathrm{PO}$ & $1.28 * * *$ & 0.01 (ni) & $0.43^{* * *}$ & $0.41^{* * *}$ & $0.0183(0.0139)$ & $-0.0058 ; 0.0483$ \\
\hline 5. $\mathrm{OP}-\mathrm{PR}-\mathrm{PO}$ & $-1.06^{* * *}$ & 0.01 (ni) & 0.01 (ni) & 0.06 (ni) & $-0.0447(0.0199)$ & $-0.0897 ;-0.0124$ \\
\hline 6. $\mathrm{OP}-\mathrm{RA}-\mathrm{PO}$ & $-1.37^{* * *}$ & $0.04^{* * *}$ & 0.01 (ni) & 0.07 (ni) & $-0.0616(0.0218)$ & $-0.1083 ;-0.0238$ \\
\hline 7. $A G-P R-P O$ & $1.22 * * *$ & $0.02 *$ & $0.26^{* * *}$ & $0.23 * * *$ & $0.0302(0.0175)$ & $-0.0001 ; 0.0690$ \\
\hline 8. AG-RA-PO & $1.27^{* * *}$ & $0.03^{* *}$ & $0.26^{* * *}$ & $0.22 * * *$ & $0.0371(0.0181)$ & $0.0057 ; 0.0782$ \\
\hline 9. $\mathrm{CO}-\mathrm{PR}-\mathrm{PO}$ & 0.46 (ni) & $0.02 *$ & $0.37^{* * *}$ & $0.35^{* * *}$ & $0.0125(0.0094)$ & $-0.0013 ; 0.0348$ \\
\hline 10. $\mathrm{CO}-\mathrm{RA}-\mathrm{PO}$ & $0.65^{*}$ & $0.02 *$ & $0.37^{* * *}$ & $0.35^{* * *}$ & $0.0179(0.0115)$ & $0.0003 ; 0.0043$ \\
\hline
\end{tabular}

$* p<0.05 ; * * p<0.01 ; 1 ; * * p<0.001$; ni-non-significant; 1. NE-PR—PO: Neuroticism-Personal religiousness-Positivity; 2. NE-RA-PO: Neuroticism-Religious attitude-Positivity; 3. EX-PR-PO: Extraversion-Personal religiousness-Positivity; 4. EX-RA-PO: Extraversion-Religious attitude-Positivity; 5. OP-PR-PO: Openness-Personal religiousness-Positivity; 6. OP-RA-PO: Openness-Religious attitude-Positivity; 7. AG-PR-PO: Agreeableness-Personal religiousness-Positivity; 8. AG-RA-PO: Agreeableness-Religious attitude-Positivity; 9 . CO-PR-PO: Conscientiousness-Personal religiousness-Positivity; 10. CO-RA-PO: Conscientiousness-Religious attitude-Positivity; a path = effect of the predictor on the mediator; $b$ path = effect of the mediator on the outcome; $c$ path = effect of the predictor on the outcome; $c^{\prime}$ path = direct effect of predictor on the outcome while controlling for the mediator. 


\section{Discussion}

The first aim of this research was to assess the association between the Big Five personality traits, life satisfaction/positivity, and personal religiousness/religious attitude. The second purpose was to examine whether personal religiousness and religious attitude mediated the relationships between personality traits and satisfaction/positivity. This research gives general support for all three hypotheses.

Firstly, the positive correlations between life satisfaction/positivity and extraversion, agreeableness, conscientiousness, and the negative association with neuroticism are consistent with the previous findings obtained across various contexts, cultures, and traditions (Gomez et al. 2009; Ha and Kim 2013; Przepiorka et al. 2019). Different studies (Hounkpatin et al. 2018) suggest that emotionally stable, cheerful and socially active, considerate and cooperative, motivated and responsible individuals are more likely to experience life satisfaction over time. In respect to openness to experience which did not show any correlation with life satisfaction/positivity, our outcomes confirm other analyses (Steel et al. 2008) where openness was significantly associated with happiness and quality of life, but it was not significantly related to life satisfaction. In accordance with some evidence (García et al. 2005), openness, which denotes receptiveness to new ideas, displays a different pattern of relationships with the other Five Factor model dimensions. Likewise, Diener (1998) noticed that openness generally is not associated on the hedonic level with whether people experience a positive effect or life satisfaction.

Secondly, we found a trend of positive correlations between personal religiousness, its dimensions, religious attitude, and extraversion, agreeableness, and conscientiousness. Simultaneously, personal religiousness, its dimensions, and religious attitude correlated negatively with openness to experience, and did not correlate with neuroticism. The current study largely replicated many previous findings. For example, Koenig and colleagues (Koenig et al. 2012) in their systematic review of fifty studies found that religiousness was positively related to extraversion in $38 \%$ of cases, negatively in $6 \%$, and unrelated in the rest of reports. Saroglou (2002) observed that religiousness was constantly linked to agreeableness and conscientiousness, related negatively to openness, and not associated with neuroticism. The application of Eysenck's model clarified and extended knowledge suggesting the lack of a relationship between neuroticism and religiosity (Taylor and MacDonald 1999).

Finally, our research offers a contribution to the field by providing evidence that extraversion, openness, agreeableness, and conscientiousness predict life satisfaction/positivity because respondents display a personal religiousness/religious attitude. This outcome is consistent with other studies that investigated the mediating role of religiosity within different frameworks of independent and dependent variables. For example, Barber (2014) revealed that people who used prayer and/or meditation in their everyday reality were more likely to perceive the benefits in their lives. It can be due to the main function of religion that consists of providing an integrated set of beliefs, personal meaning, a sense of purpose, and guidelines for living, especially in times of adversity (Park 2007). Steger and Frazier (2005) noted that the greater sense of meaning included in people's religiosity is associated with their greater confident regard for their lives and selves. Thanks to religious involvement through frequent contact with sacred individuals, they address issues that are important and meaningful, which in turn may elevate their well-being (Pargament 1997).

\section{Limitations}

This research is not free from some limitations. Given that the respondents were recruited mostly throughout a university web page and other websites, it cannot be assumed that they represent the general population. Furthermore, the sociodemographic information was limited to age, sex, working status, and residence, which reduces the opportunity for a more acute explanation of the results. Accordingly, in future studies, it would be meaningful to extend the research samples and incorporate a broader array of pertinent latent confounders that might have an impact on the findings, such as: different forms of religious commitment, subjective assessment of health, economic and marital status, and levels of education. Moreover, although we found evidence for the mediating role of religiosity on 
the relationship between personality and life satisfaction, we were unable to evaluate causation in these relationships due to the cross-sectional design adopted in the current study. Nevertheless, we examined mediation in cross-sectional data, providing a suitable basis for the advanced mediation procedure. In the future, it would be significant to use a longitudinal strategy to enhance our knowledge of how personality might affect life satisfaction through the mediating role of religiousness.

\section{Conclusions}

The study enhances our knowledge about personality traits and religiosity among Polish adults and in large part confirms prior research about the relationship between religiousness and life satisfaction/positivity. Though the correlational and mediatory nature of our outcomes does not allow us to derive a causal conclusion, the findings suggest that the co-existence of religiosity in the context of the "Big Five" dimensions may be meaningful for life satisfaction.

Author Contributions: Conceptualization, M.S., B.S. and Z.K.; Data curation, M.S.; Investigation, B.S.; Methodology, M.S. and Z.K.; Resources, Z.K.; Writing—original draft, M.S. and B.S.

Funding: This research received no external funding.

Conflicts of Interest: The authors declare no conflict of interest.

\section{References}

Aghababaei, Naser. 2014. God, the Good Life, and HEXACO: The Relations among Religion, Subjective Well-Being and Personality. Mental Health, Religion \& Culture 17: 284-90.

Aghababaei, Naser, Jason Adam Wasserman, and Drew Nannini. 2014. The Religious Person Revisited: Cross-Cultural Evidence from HEXACO Model of Personality Structure. Mental Health, Religion $\mathcal{E}$ Culture 17: 24-29.

Agler, Robert, and Paul De Boeck. 2017. On the Interpretation and Use of Mediation: Multiple Perspectives on Mediation Analysis. Frontiers in Psychology 8: 1984. [CrossRef]

Aguinis, Herman, Jeffrey R. Edwards, and Kyle J. Bradley. 2017. Improving Our Understanding of Moderation and Mediation in Strategic Management Research. Organizational Research Methods 20: 665-85. [CrossRef]

Anderson, Samantha F., Ken Kelley, and Scott E. Maxwell. 2017. Sample-Size Planning for More Accurate Statistical Power: A Method Adjusting Sample Effect Seizes for Publication Bias and Uncertainty. Psychological Science 28: 1547-62. [CrossRef]

Barber, Clifton E. 2014. Is Religiosity a Protective Factor for Mexican-American Filial Caregivers? Journal of Religion, Spirituality \& Aging 26: 245-58.

Berthold, Anne, and Willibald Ruch. 2014. Satisfaction with Life and Character Strengths of Non-Religious and Religious People: It's Practicing One's Religion that Makes the Difference. Frontiers in Psychology 5: 876. [CrossRef]

Błachnio, Agata, and Aneta Przepiórka. 2016. Personality and Positive Orientation in Internet and Facebook Addiction. An Empirical Report from Poland. Computers in Human Behavior 59: 230-36. [CrossRef]

Brief, Arthur P., Ann Houston Butcher, Jennifer M. George, and Karen E. Link. 1993. Integrating Bottom-Up and Top-Down Theories of Subjective Well-Being: The Case of Health. Journal of Personality and Social Psychology 64: 646-53. [CrossRef]

Caprara, Gian Vittorio. 2009. Positive Orientation: Turning Potentials into Optimal Functioning. The Bulletin of the European Health Psychologist 11: 46-48.

Caprara, Gian Vittorio, Guido Alessandri Guido, Gisela Trommsdorff, Tobias Heikamp, Susumu Yamaguchi, and Fumiko Suzuki. 2012a. Positive Orientation Across Three Cultures. Journal of Cross-Cultural Psychology 43: 77-83. [CrossRef]

Caprara, Gian Vittorio, Guido Alessandri, Nancy Eisenberg, A. Kupfer, Patrizia Steca, Maria Giovanna Caprara, Susumu Yamaguchi, Ai Fukuzawa, and John Abela. 2012b. The Positivity Scale. Psychological Assessment 24: 701-12. [CrossRef]

Chukwuorji, JohnBosco Chika, Ezichi Anya Ituma, and Lawrence Ejike Ugwu. 2018. Locus of Control and Academic Engagement: Mediating Role of Religious Commitment. Current Psychology 37: 792-802. [CrossRef] 
Cohen, Jacob. 1988. Statistical Power Analysis for the Behavioral Sciences. New York: Lawrence Erlbaum Associates. Costa, Paul T., and Robert R. McCrae. 1980. Influence of Extraversion and Neuroticism on Subjective Well-Being: Happy and Unhappy People. Journal of Personality and Social Psychology 38: 668-78. [CrossRef]

Costa, Paul T., and Robert R. McCrae. 1989. The NEO-PI/NEO-FFI Manual Supplement. Odessa: Psychological Assessment Resources.

Costa, Paul T., Robert McCrae, and David A. Dye. 1991. Facet Scales for Agreeableness and Conscientiousness: A Revision of the NEO Personality Inventory. Personality and Individual Differences 12: 887-98. [CrossRef]

DeNeve, Kristina M., and Harris Cooper. 1998. The Happy Personality: A Meta-Analysis of 137 Personality Traits and Subjective Well-Being. Psychological Bulletin 124: 197-229. [CrossRef]

Diener, Ed. 1998. Subjective Well-Being and Personality. In Advanced Personality. Edited by David F. Barone, Michel Hersen and Vincent B. Van Hasselt. New York: Plenum, pp. 311-34.

Diener, Ed, Robert A. Emmons, Randy J. Larsen, and Sharon Griffin. 1985. The Satisfaction with Life Scale. Journal of Personality Assessment 49: 71-75. [CrossRef]

Diener, Ed, Shigehiro Oishi, and Richard E. Lucas. 2003. Personality, Culture, and Subjective Well-Being: Emotional and Cognitive Evaluations of Life. Annual Review of Psychology 54: 403-25. [CrossRef]

Dolan, Paul, Tessa Peasgood, and Mathew White. 2008. Do We Really Know What Makes Us Happy? A Review of the Economic Literature on the Factors Associated with Subjective Well-Being. Journal of Economic Psychology 29: 94-122. [CrossRef]

Duriez, Bart, Bart Soenens, and Wim Beyers. 2004. Personality, Identity Styles, and Religiosity: An Integrative Study Among Late Adolescents in Flanders (Belgium). Journal of Personality 72: 877-910. [CrossRef]

Emmons, Robert A. 2005. Striving for the Sacred: Personal Goals, Life Meaning, and Religion. Journal of Social Issues 61: 731-45. [CrossRef]

Eysenck, Michael W. 1998. Personality and the Psychology of Religion. Mental Health, Religion \& Culture 1: 11-19.

Fairchild, Amanda J., and David MacKinnon. 2009. A General Model for Testing Mediation and Moderation Effects. Prevention Science 10: 87-99. [CrossRef]

Faul, Franz, Edgar Erdfelder, Albert-Georg Lang, and Axel Buchner. 2007. G*Power 3: A Flexible Statistical Power Analysis Program for the Social, Behavioral, and Biomedical Sciences. Behavior Research Methods 39: 175-91. [CrossRef]

Faul, Franz, Edgar Erdfelder, Axel Buchner, and Albert-Georg Lang. 2009. Statistical Power Analyses Using G*Power 3.1: Tests for Correlation and Regression Analyses. Behavior Research Methods 41: 1149-60. [CrossRef]

Ferrari, Joseph R., Jordan Reed, and Mayra Guerrero. 2017. Personality as Predictor of Religious Commitment and Spiritual Beliefs: Comparing Catholic Deacons and Men in Formation. Journal of Spirituality in Mental Health 19: 20-33. [CrossRef]

Fidell, Linda S., and Barbara G. Tabachnick. 2003. Preparatory Data Analysis. In Handbook of Psychology: Research Methods in Psychology. Edited by John A. Schinka, Wayne F. Velicer and Irving B. Weiner. Hoboken: John Wiley \& Sons, pp. 115-141.

Francis, Leslie J. 1992. Is Psychoticism Really a Dimension of Personality Fundamental to Religiosity? Personality and Individual Differences 13: 645-52. [CrossRef]

García, Luis F., Anton Aluja, Óscar García, and Lara Cuevas. 2005. Is Openness to Experience an Independent Personality Dimension? Convergent and Discriminant Validity of the Openness Domain and its NEO-PI-R Facets. Journal of Individual Differences 26: 132-38. [CrossRef]

George, Darren, and Paul Mallery. 2016. IBM SPSS Statistics 23 Step by Step: A Simple Guide and Reference. New York: Routledge.

Gomez, Veronica, Franciska Krings, Adrian Bangerter, and Alexander Grob. 2009. The Influence of Personality and Life Events on Subjective Well-Being from a Life Span Perspective. Journal of Research in Personality 43: 345-54. [CrossRef]

Ha, Shang E., and Seokho Kim. 2013. Personality and Subjective Well-Being: Evidence from South Korea. Social Indicators Research 111: 341-59. [CrossRef]

Habib, Dianne Gabriela, Casswina Donald, and Gerard Hutchinson. 2018. Religion and Life Satisfaction: A Correlational Study of Undergraduate Students in Trinidad. Journal of Religion and Health 57: 1567-80. [CrossRef]

Hahs-Vaughn, Debbie L. 2017. Applied Multivariate Statistical Concepts. New York: Routledge. 
Hayes, Andrew F. 2017. Introduction to Mediation, Moderation, and Conditional Process Analysis. New York: Guilford Publications.

Heidemeier, Heike, and Anja S. Göritz. 2016. The Instrumental Role of Personality Traits: Using Mixture Structural Equation Modeling to Investigate Individual Differences in the Relationships Between the Big Five Traits and Life Satisfaction. Journal of Happiness Studies 17: 2595-612. [CrossRef]

Henningsgaard, Jude M., and Randolph C. Arnau. 2008. Relationships between Religiosity, Spirituality, and Personality: A Multivariate Analysis. Personality and Individual Differences 45: 703-8. [CrossRef]

Hills, Peter, Leslie J. Francis, Michael Argyle, and Chris J. Jackson. 2004. Primary Personality Trait Correlates of Religious Practice and Orientation. Personality and Individual Differences 36: 61-73. [CrossRef]

Hounkpatin, Hilda Osafo, Christopher J. Boyce, Graham Dunn, and Alex M. Wood. 2018. Modeling Bivariate Change in Individual Differences: Prospective Associations Between Personality and Life Satisfaction. Journal of Personality and Social Psychology 115: 12-29. [CrossRef]

Jaworski, Romuald. 1989. Psychologiczne korelaty religijności personalnej. Lublin: KUL.

Jaworski, Romuald. 2002. Psychologiczna analiza religijności w perspektywie komunikacji interpersonalnej. Studia Psychologica 3: 143-66.

Jorm, Anthony F., and Helen Christensen. 2004. Religiosity and Personality: Evidence for Non-Linear Associations. Personality and Individual Differences 36: 1433-41. [CrossRef]

Joshanloo, Mohsen, and Samaneh Afshari. 2011. Big Five Personality Traits and Self-Esteem as Predictors of Life Satisfaction in Iranian Muslim University Students. Journal of Happiness Studies 12: 105-13. [CrossRef]

Juczyński, Zygfryd. 2001. Narzędzia pomiaru w promocji psychologii zdrowia. Warszawa: Pracownia Testów Psychologicznych PTP.

Koenig, Harold G., Dana E. King, and Verna Benner Carson. 2012. Handbook of Religion and Health. New York: Oxford University Press.

Kortt, Michael A., Brian Dollery, and Bligh Grant. 2015. Religion and Life Satisfaction Down Under. Journal of Happiness Studies 16: 277-93. [CrossRef]

Krok, Dariusz. 2014. The Mediating Role of Coping in the Relationships Between Religiousness and Mental Health. Archives of Psychiatry and Psychotherapy 2: 5-13. [CrossRef]

Łaguna, Mariola, Piotr Oleś, and Dorota Filipiuk. 2011. Orientacja pozytywna i jej pomiar: Polska adaptacja Skali Orientacji Pozytywnej. Studia Psychologiczne 49: 47-54.

Lahey, Benjamin B. 2009. Public Health Significance of Neuroticism. American Psychologist 64: 241-56. [CrossRef]

Lakens, Daniël. 2013. Calculating and Reporting Effect Sizes to Facilitate Cumulative Science: A Practical Primer for $t$-tests and ANOVAs. Frontiers in Psychology 4: 863. [CrossRef]

Lewis, Christopher Alan, John Maltby, and Liz Day. 2005. Religious Orientation, Religious Coping and Happiness among UK Adults. Personality and Individual Differences 38: 1193-202. [CrossRef]

Lomax, Richard G., and Debbie L. Hahs-Vaughn. 2012. An Introduction to Statistical Concepts. New York: Routledge/Taylor \& Francis Group.

Lucas, Richard E., Kimdy Le, and Portia S. Dyrenforth. 2008. Explaining the Extraversion/Positive Affect Relation: Sociability Cannot Account for Extraverts' Greater Happiness. Journal of Personality 76: 385-414. [CrossRef]

Luhmann, Maike, Richard E. Lucas, Michael Eid, and Ed Diener. 2013. The Prospective Effect of Life Satisfaction on Life Events. Social Psychological and Personality Science 4: 39-45. [CrossRef]

MacKinnon, David P., JeeWon Cheong, and Angela G. Pirlott. 2012. Statistical Mediation Analysis. In APA Handbook of Research Methods in Psychology. Edited by Harris Cooper. Washington, DC: American Psychological Association, pp. 313-31.

Maltby, John, Christopher Alan Lewis, and Liza Day. 1999. Religious Orientation and Psychological Well-Being: The Role of the Frequency of Personal Prayer. British Journal of Health Psychology 4: 363-78. [CrossRef]

Maltby, John, Liz Day, and Ann Macaskill. 2007. Introduction to Personality, Individual Differences and Intelligence. Essex: Pearson Education.

Martell, Richard F., David M. Lane, and Cynthia Emrich. 1996. Male-Female Differences: A Computer Simulation. American Psychologist 51: 157-58. [CrossRef]

Maxwell, Scott E., and David A. Cole. 2007. Bias in Cross-Sectional Analyses of Longitudinal Mediation. Psychological Methods 12: 23-44. [CrossRef]

McCrae, Robert R. 1999. Mainstream Personality Psychology and the Study of Religion. Journal of Personality 67: 1209-18. [CrossRef] 
Mehmetoglu, Mehmet, and Tor Georg Jakobsen. 2017. Applied Statistics Using STATA: A Guide for the Social Sciences. London: SAGE Publications.

Miciuk, Łukasz Roland, Tomasz Jankowski, Agnieszka Laskowska, and Piotr Oleś. 2016. Positive Orientation and the Five-Factor Model. Polish Psychological Bulletin 47: 141-48. [CrossRef]

Morgan, George A., and Orlando V. Griego. 1998. Easy Use and Interpretation of SPSS for Windows: Answering Research Questions with Statistics. Mahwah: Lawrence Erlbaum Associates, pp. 49-64.

Pargament, Kenneth I. 1997. The Psychology of Religion and Coping: Theory, Research, Practice. New York: Guilford Press.

Park, Crystal L. 2007. Religiousness/Spirituality and Health: A Meaning Systems Perspective. Journal of Behavioral Medicine 30: 319-28. [CrossRef]

Pourhoseingholi, Mohamad Amin, Ahmad Reza Baghestani, and Mohsen Vahedi. 2012. How to Control Confounding Effects by Statistical Analysis. Gastroenterology and Hepatology from Bed to Bench 5: 79-83.

Preacher, Kristopher J., and Andrew F. Hayes. 2008. Asymptotic and Resampling Strategies for Assessing and Comparing Indirect Effects in Multiple Mediator Models. Behavior Research Methods 40: 879-91. [CrossRef]

Prężyna, Władysław. 1968. Skala Postaw Religijnych. Roczniki Filozoficzne 16: 75-89.

Prężyna, Władysław, and Teresa Kwaśniewska. 1974. Powiązanie postawy religijnej i osobowości analizowanej w świetle danych Inwentarza Psychologicznego H. G. Gougha. Roczniki Filozoficzne 22: 5-24.

Przepiorka, Aneta, Nicolson Yat-fan Siu, Małgorzata Szcześniak, Celina Timoszyk-Tomczak, Jacqueline Jiaying Le, and Mónica Pino Muñoz. 2019. The Relationship Between Personality, Time Perspective and Positive Orientation in Chile, Hong Kong, and Poland. Journal of Happiness Studies, 1-21. [CrossRef]

Rosellini, Anthony J., and Timothy A. Brown. 2011. The NEO Five-Factor Inventory: Latent Structure and Relationships with Dimensions of Anxiety and Depressive Disorders in a Large Clinical Sample. Assessment 18: 27-38. [CrossRef]

Saroglou, Vassilis. 2002. Religion and the Five Factors of Personality: A Meta-Analytic Review. Personality and Individual Differences 32: 15-25. [CrossRef]

Saroglou, Vassilis. 2010. Religiousness as a Cultural Adaptation of Basic Traits: A Five-Factor Model Perspective. Personality and Social Psychology Review 14: 108-25. [CrossRef]

Saroglou, Vassilis. 2015. Personality and Religion. In International Encyclopedia of the Social and Behavioral Sciences. Edited by James D. Wright. Oxford: Elsevier, pp. 801-8.

Saroglou, Vassilis, and Antonio Muñoz-García. 2008. Individual Differences in Religion and Spirituality: An Issue of Personality Traits and/or Values. Journal of the Scientific Study of Religion 47: 83-101. [CrossRef]

Schimmack, Ulrich, Shigehiro Oishi, R. Michael Furr, and David Funder. 2004. Personality and Life Satisfaction: A Facet-Level Analysis. Personality and Social Psychology Bulletin 30: 1062-75. [CrossRef]

Schnell, Tatjana. 2012. Spirituality with and without Religion-Differential Relationships with Personality. Archive for the Psychology of Religion 34: 33-61. [CrossRef]

Sinnewe, Elisabeth, Michael A. Kortt, and Brian Dollery. 2015. Religion and Life Satisfaction: Evidence from Germany. Social Indicators Research 123: 837-55. [CrossRef]

Śliwak, Jacek, and Rafał P. Bartczuk. 2011. Skala Intensywności Postawy Religijnej. In Psychologiczny pomiar religijności. Edited by Marek Jarosz. Lublin: Towarzystwo Naukowe KUL, pp. 153-68.

Soto, Christopher J., Oliver P. John, Samuel D. Gosling, and Jeff Potter. 2011. Age Differences in Personality Traits From 10 to 65: Big Five Domains and Facets in a Large Cross-Sectional Sample. Journal of Personality and Social Psychology 100: 330-48. [CrossRef]

South, Susan C., Amber M. Jarnecke, and Colin E. Vize. 2018. Sex Differences in the Big Five Model Personality Traits: A Behavior Genetics Exploration. Journal of Research in Personality 74: 158-65. [CrossRef]

Steel, Piers, Joseph Schmidt, and Jonas Shults. 2008. Refining the Relationship Between Personality and Subjective Well-Being. Psychological Bulletin 134: 138-61. [CrossRef]

Steger, Michael F., and Patricia Frazier. 2005. Meaning in Life: One Link in the Chain from Religiousness to Well-Being. Journal of Counseling Psychology 52: 574-82. [CrossRef]

Stolarski, Maciej, and Gerald Matthews. 2016. Time Perspectives Predict Mood States and Satisfaction with Life over and above Personality. Current Psychology 35: 516-26. [CrossRef]

Sullivan, Kieran. 2001. Understanding the Relationship between Religiosity and Marriage: An Investigation of the Immediate and Longitudinal Effects of Religiosity on Newlywed Couples. Journal of Family Psychology 15: 610-26. [CrossRef] 
Szcześniak, Małgorzata, Grażyna Bielecka, Iga Bajkowska, Anna Czaprowska, and Daria Madej. 2019. Religious/Spiritual Struggles and Life Satisfaction among Young Roman Catholics: The Mediating Role of Gratitude. Religions 10: 395. [CrossRef]

Taylor, Andrew, and Douglas A. MacDonald. 1999. Religion and the Five Factor Model of Personality: An Exploratory Investigation Using a Canadian University Sample. Personality and Individual Differences 27: 1243-59. [CrossRef]

ten Kate, Josje, Willem de Koster, and Jeroen van der Waal. 2017. The Effect of Religiosity on Life Satisfaction in a Secularized Context: Assessing the Relevance of Believing and Belonging. Review of Religious Research 59: 135-55. [CrossRef] [PubMed]

Thompson, Christopher Glen, Rae Seon Kim, Ariel M. Aloe, and Betsy Jane Becker. 2017. Extracting the Variance Inflation Factor and Other Multicollinearity Diagnostics from Typical Regression Results. Basic and Applied Social Psychology 39: 1-10. [CrossRef]

Tian, Lili, Dandan Zhang, and E. Scott Huebner. 2018. Psychometric Properties of the Positivity Scale among Chinese Adults and Early Adolescents. Frontiers in Psychology 9: 197. [CrossRef] [PubMed]

Unterrainer, Human Friedrich, Karl Heinz Ladenhauf, Maryam Laura Moazedi, Sandra Johanna Wallner-Liebmann, and Andreas Fink. 2010. Dimensions of Religious/Spiritual Well-Being and their Relation to Personality and Psychological Well-Being. Personality and Individual Differences 49: 192-97. [CrossRef]

Vater, Aline, and Michela Schröder-Abé. 2015. Explaining the Link Between Personality and Relationship Satisfaction: Emotion Regulation and Interpersonal Behaviour in Conflict Discussions. European Journal of Personality 29: 201-15. [CrossRef]

Weidmann, Rebekka, Thomas Ledermann, and Alexander Grob. 2017. Big Five Traits and Relationship Satisfaction: The Mediating Role of Self-Esteem. Journal of Research in Personality 69: 102-9. [CrossRef]

Wink, Paul, Lucia Ciciolla, Michele Dillon, and Allison J. Tracy. 2007. Religiousness, Spiritual Seeking, and Personality: Findings from a Longitudinal Study. Journal of Personality 75: 1051-70. [CrossRef]

Xu, Le, Ru-De Liu, Yi Ding, Xiaohong Mou, Jia Wang, and Ying Liu. 2017. The Mediation Effect of Coping Style on the Relations between Personality and Life Satisfaction in Chinese Adolescents. Frontiers in Psychology 8: 1076. [CrossRef]

Yeniaras, Volkan, and Tugra Nazli Akarsu. 2017. Religiosity and Life Satisfaction: A Multi-dimensional Approach. Journal of Happiness Studies 18: 1815-40. [CrossRef]

Zarzycka, Beata, Dominika Ziółkowska, and Jacek Śliwak. 2017. Religious Support and Religious Struggle as Predictors of Quality of Life in Alcoholics Anonymous-Moderation by Duration of Abstinence. Roczniki Psychologiczne 20: 121-42. [CrossRef]

Zawadzki, Bogdan, Jan Strelau, Piotr Szczepaniak, and Magdalena Śliwińska. 1998. Inwentarz Osobowości NEO-FFI Costy i McCrae. Adaptacja polska. Warszawa: Pracownia Testów Psychologicznych PTP. 